\title{
Том \\ Searching for the Sources of the Nile through a podcast: what did we find?
}

\section{Emanuele Fantini and Emilie Buist}

\begin{abstract}
Podcasts are gaining traction in academic practice and debates. This article reflects on the experience of "The Sources of the Nile", a podcast on media, science, and water diplomacy. By presenting the podcast structure and production process, we sketch a "podcast pathway" that might serve as a guide for others. We share the results of a survey conducted among our listeners and we review the episodes discussing what we learned on distributions of voice, knowledge and water in the Nile basin. We conclude by reflecting on the connection between the technical production of the podcast and the type of knowledge that it generates, and by pointing at the importance of placing the podcast within a broader community of interests and practice.
\end{abstract}

Keywords

DOI

Environmental communication; Science and media; Science communication in the developing world

https://doi.org/10.22323/2.20020801

Submitted: 8th July 2020

Accepted: 8th December 2020

Published: 22nd February 2021

Introduction

"Welcome to The Sources of the Nile: a podcast about media, science, and water diplomacy in the Nile basin". Thus begins what we consider one of the most enjoyable and rewarding activities undertaken within the project "Open Water Diplomacy: media, science and trans-boundary cooperation in the Nile basin" (hereafter OWD). The OWD project involves journalists and researchers from Nile basin countries in an action research project to explore the role of media and science communication in conflicts and cooperation over the management and sharing of the Nile's water. ${ }^{1}$

\footnotetext{
${ }^{1}$ The project is funded by the Dutch Ministry of Foreign Affairs and it is implemented by IHE Delft Institute for Water Education (The Netherlands), Africa Water Journalists (a network of Sub-Saharan environmental journalists), Nile Basin Capacity Building Network (water researchers and professionals from Nile countries), Scidev.net (an organization working on training and capacity building on science communication for development), and the Media Studies Department of the University of Witwatersrand (Johannesburg, South Africa).
} 
The OWD project consists of three main activities: $i$ ) research on Nile narratives in the Egyptian, Sudanese, Ethiopian, Ugandan and global media; ii) online and residential trainings on water science communication; and iii) reporting grants to support the co-production of knowledge and information by journalists and researchers. We embarked on this action research as the building of the Grand Ethiopian Renaissance Dam (GERD) along the Blue Nile river was - and still is sparking tensions between Egypt, Sudan, and Ethiopia, with rumors about the next "water war brewing over the river" striking back in media headlines. ${ }^{2}$

Indeed, the media are often accused of exacerbating the conflict, by disseminating inaccurate information, or fabricating tensions through sensational reports. On the other side, the media are also considered part of the solution by several international institutions (like the Nile Basin Initiative - NBI, Stockholm International Water Institute - SIWI, or the German International Development Agency - GIZ) trying to promote a more constructive coverage of Nile issues through journalists' training and grants. ${ }^{3}$

OWD aims at contributing to these efforts by focusing on the interaction and collaboration between journalists and researchers. One of the project's assumptions is that improving the communication of techno-scientific facts requires a double effort: while journalists should get a deeper knowledge of water facts, researchers have to boost their communication skills to present those facts in a clear and accessible way.

However, such efforts might not be sufficient, since politics often dictate the space for and the use of scientific information in public debates. This is definitely the case of a highly securitized river like the Nile, where the space for critical voices challenging the national governments' official narratives is extremely limited. The podcast "The Sources of the Nile" is part of OWD endeavor to engage journalists and researchers in a "trans-boundary" conversation to explore and promote alternative narratives on the river. The podcast was conceived to communicate and discuss preliminary research findings, to strengthen relations within the project, to extend the network to other key actors, and to reflect on our ongoing work.

While searching for inspiration and guidance in the literature on academic and science communication podcasting, we realized that the debate mainly focuses on the use, efficacy, and impact of podcasts in education [Hew, 2009; Heilesen, 2010; Fernandez, Sallan and Simo, 2015], particularly to engage and activate students [Lee, McLoughlin and Chan, 2008; Armstrong, Tucker and Massad, 2009; Popova and Edirisingha, 2010; Pegrum, Bartle and Longnecker, 2015]. Our interest mainly lies in exploring the potential of podcasting in research. We consider ourselves as "independent" or non-professional podcasters [Markman, 2012], and our podcast is made for and with a community of peers. Involving user-led content production within a community of interest and practice, we consider our experience as a form of produsage [Bruns, 2008].

\footnotetext{
${ }^{2}$ See for instance BBC, The 'water war' brewing over the new River Nile dam, https: / / www.bbc.com/news/world-africa-43170408, 24 February 2018 (visited 6 July 2020).

${ }^{3}$ See for instance SIWI enables unique media dialogue in the Eastern Nile Basin, https: / / www.siwi.org/latest/ siwi-enables-unique-media-dialogue-in-the-eastern-nile-basin/, 10 August 2016 (visited 6 July 2020).
} 
In the first part of the article, we sketch a "podcast pathway" to describe the process of podcast production that might serve as a guide for other colleagues interested in starting their own podcasts. We illustrate the pathway by presenting the choices we made in our podcast, and we reflect on those also in light of the results of a survey conducted among our listeners [Gay et al., 2007].

In the second part, by reviewing the content of different episodes, we discuss how distributions of voices and knowledge are interwoven with distributions of water [Zwarteveen et al., 2017] in the Nile basin. We also reflect on how the podcast was instrumental in generating new knowledge and informing the other activities of the project.

We conclude with a reflection on how the "technical" process of podcast production and the "political" content generated, interweave around the notions of voice, recognition, and relation. Furthermore, we point at the importance of placing the podcast within a broader community of interests and practice.

The process: design, production and distribution
In this section, we want to give a taste of what it can be like to start making a podcast. In hindsight, the process can be boiled down to three parts: the podcast design, the podcast production, and the podcast distribution. We present the process in a circular way to emphasise its iterative nature (Figure 1). Below we share the considerations and the choices eventually made for each step. The reflection on the process is also informed by the outcomes of an online survey conducted among our listeners to get feedback after the completion of the first season of eight episodes, in December 2018. The survey, consisting of 10 mostly multiple-choice questions, was filled in by 29 respondents. Since each episode got an average of one hundred plays during the first month, we consider the amount of responses fairly representative of our "serial listeners".

\section{Podcast design: general outline and planning}

At first, to design the overall outline and plan of the podcast we gathered as much information as possible through online courses, ${ }^{4}$ blogs, video tutorials, and even podcasts about podcasting. Furthermore, we got inspired by other podcasts projects and we met with two experienced journalists to gain more awareness of the issues to consider.

The first question to ask is about the objectives of the podcast: why do we want to do it? From that follows the identification of topic(s) and audience(s). In our case, we wanted to facilitate a conversation between journalists and researchers interested in the Nile, to communicate and discuss preliminary research findings, to strengthen relations within the project, as well as to extend the network to other key actors. The respondents of the survey confirmed that they considered our podcast as a great way to disseminate new information and ideas (22 respondents), that they could discover interesting guest speakers (18 respondents), and that the podcast was a nice way to pay a tribute to a legendary river (12 respondents).

\footnotetext{
${ }^{4} \mathrm{~A}$ useful and open access introductory guide to podcasting in higher education is the one by the Irish project All Aboard, https:/ / rise.articulate.com/share/3B1ld0TuNQkBrhUR\#/.
} 


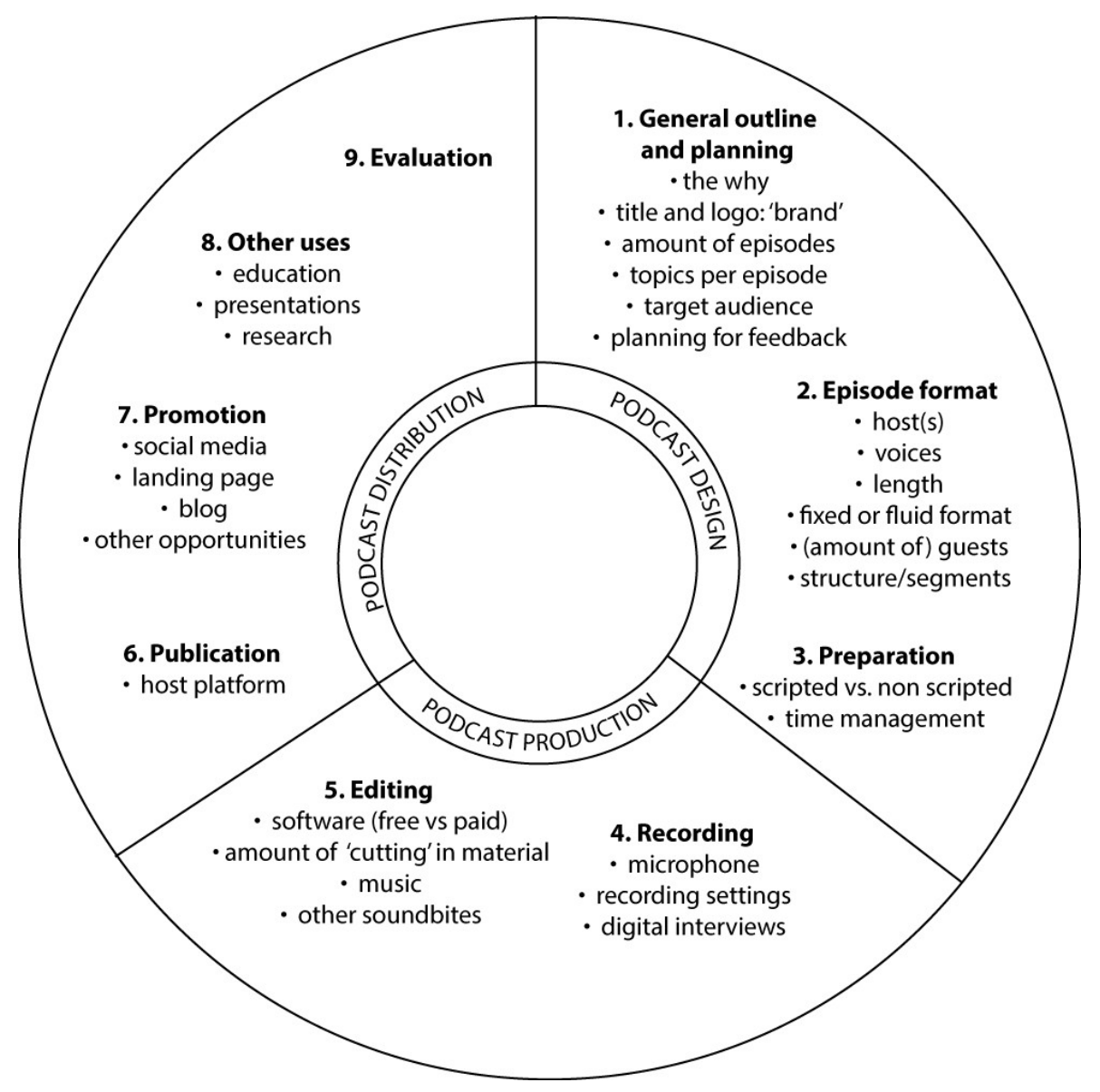

Figure 1. The podcast pathway.

In terms of audience, we knew that the topic of our podcast was quite specific. From the total of 29 survey responses of listeners, more than a half (16) declared to be "highly familiar with the topic", working on Nile or media, and another third (9) declared to be "rather familiar", working on water and/or media issues. In other words, our audience is composed of "water-nerds-who-have-been-waiting-for-a-podcast-on-Nile-geopolitics" as tweeted by one of them. This resonates with the observation that podcasts in general "attract people who are already somewhat interested in the subjects covered in the podcast they subscribe" [Birch and Weitkamp, 2010, p. 892].

Such "long tail" [Anderson, 2004] composition of the audience - few but committed - should be considered when planning how to get feedback to evaluate and improve the podcast. The spontaneous feedback via email or social media received from the listeners, helped us to better calibrate the content: for instance, the last episode "Who speaks for the river?" was triggered by a Twitter comment in reaction to an earlier episode. Later, we decided to conduct a survey to assess the first eight episodes of the podcast and to plan a second series. While the new series has not materialised yet, the survey's outcomes have been useful to confirm some of our choices, and to prompt for ideas to be applied later to other projects. We therefore strongly recommend planning for formative evaluation right from the start of the podcast and to actively involve the audience in it, as suggested by Weitkamp and Featherstone [2009]. Listening to our listeners and taking up their 
observations also contributed to creating a sense of community and identification around the podcast.

The podcast title summarises the topic and represents the brand. Therefore, it needs careful consideration. We chose "The Sources of the Nile", playing with the dual meaning of the word "source" to reflect both the media and water part of our topic. We prepared for eight monthly episodes, and scheduled the specific topics ahead, although there was also room for adjustment. We planned the episodes also in relation to other project events, like workshops or conferences, to take advantage of guest speakers, to reflect on those events, and to include the participants as an audience.

\section{Episode format}

Like a blog or an article, a podcast also has different sections, which consist at least of an intro, a main body, and an outro. There are several options in terms of elements to add, such as interviews, discussion amongst hosts, chatting, a fiction element (story), advertisements, or sound bites and music. An important choice is who is going to host the podcast, as this will be the most recurring voice of each episode. One host makes it more controllable and usually replicates the interview format, whereas several hosts can give the feeling of a more informal conversation. Diversity in voices - male, female, accents, etc. - makes it easier for the listener to know who is speaking.

We chose to have Emanuele Fantini as our host, as he was also the overall coordinator of OWD. After an intro with an announcement of the different elements and guests for that episode, we have a recurring section called "Voices of the Nile", in which one question is shortly answered by several speakers. Next are two sequential interviews: first an interview with Guest 1 for about 10 minutes, then a short reflection on the interview, followed by an introduction to the next interview with Guest 2, also for 10 minutes. The episode finishes with a concluding reflection by Emanuele to recap the main ideas and message of the talks. Generally, the format was well received by the respondents of our survey, although the pace was said to be a bit high. In retrospect, we may have made the episode too dense with information.

\section{Episode preparation}

Another choice is the amount of preparation put into the recording. Even seemingly informal discussions could be prepared and scripted. Aligned with this is the time management of the podcast: will you stop the interview after a scheduled amount of time, or will you let it flow (and decide in editing whether and how to shorten it). This depends on your choice on the length of the podcast, and your idea of the concentration span of your listeners. Over time, we scripted less and improvised more, and felt this gave more natural-sounding conversations. We were wondering whether the total length (around 30 minutes) might be too long or too short. Some 22 respondents (75\%) agreed that this was a good length, suggesting that we were on the right track. 
Subsequently comes the moment that you will have to start recording the material. To record the audio there are several types of microphones and recorders with different features and sound qualities on the market. Not going into the technical details of these, we learned that sound quality does make a difference to whether people like to listen, and it also reflects your "brand" and professionalism. Personally, we had difficulties finding a quiet recording space inside our Institute. We tried different settings and sometimes had to compromise. The sound quality and editing were perceived as good, although there is room for improvement. Scouting a good place to record and sound checking will definitely be beneficial if you are planning to record something yourself. Pay attention to ventilators or circulation systems that should be turned off when recording.

A whole different story is the recording of remote interviews. We encountered difficulties with access to different platforms and bad internet connection. To talk to our guests and record the conversation as a back-up, we mostly relied on Skype (except for countries where it is blocked, like Egypt). To improve audio quality, we asked our guests to record their voices themselves with a mobile phone (or any other better option recording device available), and we did the same by recording Emanuele's voice with a good microphone.

\section{Editing}

For editing, we used a paid version of Adobe Suite (Audition), given prior experience with the video software and its advanced functionalities. However, there is some free software available, such as Audacity. When working with MSc students that had to produce a podcast as an assignment, we saw that they could quickly learn how to use Audacity mostly relying on online video tutorials.

Discussions and tutorials about podcasting usually present editing as a technical process [Fernandez, Sallan and Simo, 2015]. Here we would like to foreground its political dimension. When editing a podcast you decide when to allow or silence a voice. In our experience, the technical choices made in design and preparation of each episode also have implications in terms of how much the editor(s) will later have to intervene in the flow of the talk. The more informal we got in our conversations, the longer the interviews became, requiring a lot of editorial choices in terms of sentences or parts to cut. As we aimed to stay around 30 minutes per episode, we found that sending the questions to the guests in advance and asking them to write down some notes about their answers, helped in keeping the conversation shorter and focused.

Music is a key resource in the editing process. It can accompany the transition from one section to another, and it should delight the listeners. Of course, copyright issues have to be considered. We got permission to use the music of the Nile Project, a collective of musicians from different riparian countries, which perfectly resonated with the spirit of our podcast. 
There are several hosting and distribution platforms that automatically upload your podcast on broadcasting apps, such as Libsyn, Blubrry, or Podbean. We chose to start with Soundcloud, which is free for the first 300 minutes uploaded, and once used we changed it to a paid subscription. We chose it because it is user friendly and the player can be easily embedded in your own website, in our case nilewaterlab.org/podcast. Later we added our content to Apple Podcasts. Nowadays, Spotify is also streaming podcasts, and a good option to take into account.

\section{Promotion}

We used several social media and channels to promote the podcast amongst our networks and to attract new listeners. First, we used our personal accounts on Twitter and Facebook. Emanuele also posted the links to the episodes on his academic social platforms (Academia.edu and ResearchGate). However, on the latter we got only a few views and much less engagement than on Twitter and Facebook. This suggests that academic social platforms are not effective for unconventional research products like podcasts.

Second, we used the Facebook page of the Nile Water Lab, the website hosting our podcast. As this page is not particularly active, the results were limited. Having a specific social media account for the podcast, or for the project that hosts it, can definitely be an effective channel for its distribution. ${ }^{5}$ The flipside is that it requires time and energy for regular updates and content production. Some of the episodes were also embedded in a post published on FLOWs, the blog of IHE Delft Water Governance Chair group.

Third, we asked for support from the institutional social media channels of the project partners, and in particular, we were backed with enthusiasm by IHE Delft Communication Office, also because this was the first podcast produced by the Institute. Furthermore, we thought we could rely on the social networks of the podcasts' guests. This had mixed results, depending on the enthusiasm and the number of followers of each guest.

Finally, a few "serial listeners" have been the most enthusiastic promoters of the podcast on social media: acknowledgement in public and in private is key to nurture support. Retrospectively, a more thorough communication strategy, with clear targets and explicit indications for all these channels, would have probably helped us to reach a wider audience or to elicit additional debates around the episodes.

The podcast triggered offline discussions for seven out of 29 of our respondents, and online discussions for six respondents. Two-thirds of the respondents said that they were interested in participating in an online discussion on the content of each episode, through a platform integrated with the podcast. Some suggested creating a landing page with text and additional resources, such as links to books, articles,

\footnotetext{
${ }^{5}$ An inspiring example is the podcast "Disaster: deconstructed", https:/ / twitter.com/DisastersDecon, hosted by Ksenia Chmutina and Jason von Meding.
} 
and music mentioned in the episodes. This resonates with what was observed by Birch and Weitkamp [2010]: podcasts can facilitate online conversations when combined with other discussion spaces, such as blogs and forums.

\section{Other uses of the podcast}

Finally, the podcast can also serve other purposes, like research, presentations, or education. We used it to flip the classroom, asking students to listen to a specific episode ahead of a lecture on media and water diplomacy. It was also embedded in the online course Science Communication Skills for Water Cooperation and Diplomacy offered by the OWD project. In the rush to online education generated by the Covid-19 pandemic, the podcast proved as a useful and ready-to-use resource. Learning from this experience we would advise to plan such additional uses already in the podcast design phase to better serve those purposes.

\section{Evaluation}

The whole process is iterative and not always linear. We conducted a formal evaluation at the end of the first season. Retrospectively, the lessons described above often appeared along the path, also through constant feedback and interaction with the listeners. As already mentioned, we therefore recommend to plan for formative and summative evaluation right from the start of the podcast. The development and the learning will never stop, which makes the process extremely interesting.

The content: on water, voices, and knowledge
At IHE Delft Water Governance Department, we conceptualize water governance in terms of the distribution of $i$ ) voice and authority, ii) expertise and knowledge, and - of course - iii) water. From an analytical point of view, this allows for an interdisciplinary exploration of where water flows, who makes decisions about these flows, and which knowledge informs and legitimizes such decisions. From a political point of view, this approach calls for foregrounding issues of equity and justice in water governance. The interplay of these three types of distributions emerged also in our podcast, and it can be used as a thread to account for what we learnt throughout its episodes.

\section{Distribution of voices}

When it comes to a podcast, voice is of course the most relevant and straightforward kind of distribution to account for. Throughout the podcast we have been trying to host as many different voices as possible, to reflect the plurality of interests and perspectives on the Nile river. Through the section "Voices of the Nile", we tried to convey this message in a lively and engaging way.

Such plurality was also reflected in the selection of our guests: we gave voice to different professions (mostly researchers and journalists), disciplines (from hydrology to anthropology), and nationalities (both from outside and within the Nile basin, with a focus on Ethiopia, Sudan, and Egypt). Thinking of podcasting as 
"an exercise of citizenship" [Picardi and Regina, 2008], we tried to facilitate a conversation between voices that usually are not heard in mainstream debates, like local researchers or independent journalists, and more institutional ones, like the BBC Africa correspondent or a communication officer of the Nile Basin Initiative.

English was used as the lingua franca to allow communication between all these people. The choice had of course implications in terms of audience, allowing to cater for the international public fascinated by the Nile, but perhaps excluding local listeners in the riparian countries that prefer national languages. The choice of English also reflects the podcast goal of promoting a transnational conversation and narratives on the river to challenge mainstream perspectives based on the notion of national interest.

In hosting these voices we learnt two main lessons on recognition and representation. The fact that many of our guests told us that they felt honored and delighted to join the podcast, confirmed its potential in terms of fostering personal relations [Markman and Sawyer, 2014]. Inviting people, listening to their experience, and publicly casting their voice was perceived as a recognition of their authority and knowledge, and helped us to develop personal and professional relations for the overall OWD project.

We also realized how often in Nile media debates the riparian states are personified: Egypt, Ethiopia, and Sudan speak with one voice - usually that of politicians - , they feel emotions like fear or anger, they perform on the stage of diplomatic negotiations. In this representation, the voice of the river is missing, in spite of it being a real living body full of animals and plants. As several rivers like the Ganges and Yamuna (India) or the Rio Atrato (Colombia) have been granted the status of a legal person, in the final episode we tried to give voice to the Nile itself, asking journalists and scientists who and how can represent or speak for the river.

\section{Distribution of knowledge}

The political dimension of water knowledge and expertise has been one of the podcast's recurrent topics. We began in episode 1 with Zaki Shubber (lawyer at IHE Delft) and Yasir Mohamed (professor of hydrology at IHE Delft and at Hydraulics Research Centre-Sudan) offering a definition of water diplomacy and reflecting on the role that science plays therein. Interestingly, a year after recording the interview, Yasir became the Minister of Water in the Sudan Transitional Government and he is now actively involved in the GERD negotiations with Egypt and Ethiopia. In episode 3, Rawia Tawfik (political scientist at Cairo University) highlighted the political dimension of technical data, recalling the difficulties of agreeing on baseline data to assess the impact of the GERD.

Another key topic was the collaboration between different kinds of expertise, namely journalists and researchers. While in the project we initially focused on the frictions between these two categories, in episode 5, Sudanese journalist Omnia Shawkat stressed that they also have much in common: both journalists and researchers try to represent reality, and in this endeavor they also manufacture it. She also recalled that data and science can be contradicting and that journalists have to account for uncertainty in scientific debates too. Another meaningful 
recommendation was given in episode 3 by the Egyptian journalist Ayah Aman, who suggested to involve in the conversation not only the journalists specialized on water issues, but also their editors, as the latter are the ones setting the media agenda.

Finally, we discovered that hydro-politics is also influenced by knowledge and expertise that is not usually associated with policymaking or international negotiations. In episode 2 we explored the role of emotions in building narratives on the GERD in Ethiopia and their implications for water diplomacy, together with Wondwosen Seide (an Ethiopian Ph.D. student at the University of Lund). In episode 4 we were joined by historian, geographer and filmmaker Terje Tvedt (University of Oslo) and by Linda Lilienfeld (director of the film festival "Let's talk about Water") to discuss the power of films and video in shaping popular imaginaries about the Nile, by connecting sciences with emotions. In episode 7 we discussed with Alia Mossallam (an Egyptian researcher affiliated to the Alexander Von Humboldt Foundation at the Freie Universität in Berlin) how songs have been used in Egyptian popular culture to transmit knowledge on water and technology during and after the construction of the High Aswan Dam.

In the same episode, ethnomusicologist Mina Girgis shared the experience of The Nile Project, a collective of musicians from different Nile countries using music to generate interest in the river and elicit a transnational conversation on the sharing of its waters. We got inspired by their experience of dialogic conversation. A conversation is dialogic when "though no shared agreement might be reached, through the process of exchange people might become more aware of their own views and expand their understanding of one another" [Sennett, 2012, p. 19]. The music in the Nile Project did not lead to the creation of a new Nile identity trumping the national ones, but rather it was used to establish connections between different rhythms, scales, instruments, and languages. By acknowledging such differences, and establishing connections, the musicians could reflect on and rethink their own identity. This enabled them to find a way to collaborate. A lesson that can be useful for journalists, researchers, and water diplomats alike.

\section{Distribution of water}

How do voice, knowledge, and their narratives impact the distribution of Nile waters? A recurrent argument in our conversation has been the need to unpack the idea of national interest, to reflect the plurality of positions existing within each country. In episode 5, anthropologist Tamer Abd Alkreem (University of Khartoum) discussed how political identities in Sudan are defined also in relation to the Nile, for instance, "the people of the river" vs. "the people of the desert". Such identities result in competing ideas about development and modernity in the use of water, as well as in conflicts around irrigation and dams.

A second narrative that has been challenged throughout the podcast is the "water wars". As we learned from local journalists and researchers, this frame transforms water into a national security issue, and thus closes the space for freedom of information, critical debate, and dissent. Our journey has indeed been an exploration of alternative narratives that could enable us to think about more just and sustainable uses of Nile waters. For instance, asking "who speaks for the 
river?" (episode 8), allowed to bring water pollution issues to the foreground, which are usually neglected in water diplomacy debates.

\section{Conclusion}

Our podcasting experience supports results of past surveys on the motivations of independent podcasters: "doing radio, making friends, and having fun" [Markman, 2012]. In doing radio we learnt both about process and content, and how the two interweaves voice, recognition, and relation.

Podcasting is first and foremost about voices. The seemingly technical processes of podcast design and editing also have a relevant political dimension, in terms of choices about whose voices are hosted and when they get silenced. A podcast is a versatile, easily producible, and accessible medium. This allowed us to publicly cast voices that are not usually heard in mainstream debates, like those of local journalists and researchers. It gave us new insights on how the distribution of voices and knowledge is linked to the distribution of water in the Nile basin. Several of these findings have been taken up within the community of journalists and researchers of the OWD project.

Making voices heard, listening to people's experience, and acknowledging different expertise was perceived as a recognition of their authority and knowledge. Thus the podcast proved effective media to make friends too. It helped us to develop and nurture personal and professional relations, through recognition, dialogue, and feedback. The podcast elicited a conversation not only with our guests but also with the listeners. Their feedback helped us in tuning some of the episodes and in planning future podcasting activities. The podcast also generated interest in our work from outside that community, creating new connections and collaborations with partners in the Brahmaputra and Lake Chad basins.

We had a lot of fun podcasting too. Finding it an enjoyable and rewarding experience, we embarked on a new podcast in collaboration with the journal Water Alternatives, to present and discuss the journal's special issues. Later we also used podcasting in education, learning from students' experiences and creativity as well.

Our exploration of the Sources of the Nile through a podcast ends with two main lessons learned. First: strategic planning, design, iteration, and formative evaluation are not only key technical aspects to produce a good communication product. They are also political choices that ultimately shape the knowledge produced and shared through the podcast. Second: podcasting holds great potential for generating and nurturing relations. Therefore, rather than as a stand-alone product, a podcast should be designed and placed within a broader community of interests and practice to create or improve relations. our guests for their contribution and our listeners for their feedback on the podcast and on this article; the Nile Project for their music and inspiration; the colleagues of IHE Delft Communication office for their encouragement and support; two anonymous reviewers for their comments to a previous version of this article. The podcast and this article have been supported by IHE Delft Global Partnership for 
Water and Development funded by the Dutch Ministry of Foreign Affairs. Usual disclaimers apply.

\section{References}

Anderson, C. (10th January 2004). 'The long tail'. Wired.

URL: https://www.wired.com/2004/10/tail/.

Armstrong, G. R., Tucker, J. M. and Massad, V. J. (2009). 'Interviewing the experts: student produced podcast'. Journal of Information Technology Education: Innovations in Practice 8, pp. 79-90.

Birch, H. and Weitkamp, E. (2010). 'Podologues: conversations created by science podcasts'. New Media \& Society 12 (6), pp. 889-909. https://doi.org/10.1177/1461444809356333.

Bruns, A. (2008). Blogs, Wikipedia, Second Life, and beyond: from production to produsage. New York, NY, U.S.A.: Peter Lang.

Fernandez, V., Sallan, J. M. and Simo, P. (2015). 'Past, present, and future of podcasting in higher education'. In: Exploring learning \& teaching in higher education. Ed. by M. Li and Y. Zhao. Berlin and Heidelberg, Germany: Springer, pp. 305-330. https://doi.org/10.1007/978-3-642-55352-3_14.

Gay, P. L., Bemrose-Fetter, R., Bracey, G. and Cain, F. (2007). 'Astronomy Cast: evaluation of a podcast audience's content needs and listening habits'. Communicating Astronomy with the Public 1 (1), pp. 24-29.

Heilesen, S. B. (2010). 'What is the academic efficacy of podcasting?' Computers $\mathcal{E}$ Education 55 (3), pp. 1063-1068. https://doi.org/10.1016/j.compedu . 2010.05.002.

Hew, K. F. (2009). 'Use of audio podcast in K-12 and higher education: a review of research topics and methodologies'. Educational Technology Research and Development 57 (3), pp. 333-357. https://doi.org/10.1007/s11423-008-9108-3.

Lee, M. J. W., McLoughlin, C. and Chan, A. (2008). 'Talk the talk: learner-generated podcasts as catalysts for knowledge creation'. British Journal of Educational Technology 39 (3), pp. 501-521. https://doi.org/10.1111/j.1467-8535.2007.00746.x.

Markman, K. M. (2012). 'Doing radio, making friends, and having fun: exploring the motivations of independent audio podcasters'. New Media E Society 14 (4), pp. 547-565. https://doi.org/10.1177/1461444811420848.

Markman, K. M. and Sawyer, C. E. (2014). 'Why pod? Further explorations of the motivations for independent podcasting'. Journal of Radio $\mathcal{E}$ Audio Media 21 (1), pp. 20-35. https://doi.org/10.1080/19376529.2014.891211.

Pegrum, M., Bartle, E. and Longnecker, N. (2015). 'Can creative podcasting promote deep learning? The use of podcasting for learning content in an undergraduate science unit'. British Journal of Educational Technology 46 (1), pp. 142-152. https://doi.org/10.1111/bjet.12133.

Picardi, I. and Regina, S. (2008). 'Science via podcast'. JCOM 07 (02), C05. https://doi.org/10.22323/2.07020305.

Popova, A. and Edirisingha, P. (2010). 'How can podcasts support engaging students in learning activities?' Procedia - Social and Behavioral Sciences 2 (2), pp. 5034-5038. https://doi.org/10.1016/j.sbspro.2010.03.816.

Sennett, R. (2012). The craftsman. London, U.K.: Penguin Books.

Weitkamp, E. and Featherstone, H. (2009). 'Often overlooked: formative evaluation in the development of ScienceComics'. JCOM 08 (04), A04.

https://doi.org/10.22323/2.08040204. 
Zwarteveen, M., Kemerink-Seyoum, J. S., Kooy, M., Evers, J., Guerrero, T. A., Batubara, B., Biza, A., Boakye-Ansah, A., Faber, S., Cabrera Flamini, A., Cuadrado-Quesada, G., Fantini, E., Gupta, J., Hasan, S., Horst, R., Jamali, H., Jaspers, F., Obani, P., Schwartz, K., Shubber, Z., Smit, H., Torio, P., Tutusaus, M. and Wesselink, A. (2017). 'Engaging with the politics of water governance'. Wiley Interdisciplinary Reviews: Water 4 (6), e1245. https://doi.org/10.1002/wat2.1245.

Authors

Emanuele Fantini is Senior lecturer and researcher in Water Politics and Communication at the Department of Water Governance of IHE Delft Institute for Water Education (The Netherlands). Committed to public engagement and crossover projects with artists and journalists, he coordinates the project "Open Water Diplomacy. Media, science and transboundary cooperation in the Nile basin", he hosts the podcasts "The Sources of the Nile" and "Water Alternatives Podcast", and he is the editor of IHE Delft Water Governance Blog, FLOWs. He is also affiliated to the Department of Human Geography, Planning and International Development Studies, University of Amsterdam (The Netherlands).

E-mail: e.fantini@un-ihe.org.

Emilie Buist has specialized in both water resource management and science communication within a double master degree. Through her company Cloud 22 she has produced and contributed to several water related podcasts and videos, such as "The Sources of the Nile", and co-hosts the "Water Alternatives Podcast". Currently she is employed in the Valorisation Centre of Delft University of Technology, creating links between entrepreneurs, the university and practice to stimulate innovation in the field of water management.

E-mail: emiliebuist@hotmail.com.

\section{How to cite}

Fantini, E. and Buist, E. (2021). 'Searching for the Sources of the Nile through a podcast: what did we find?'. JCOM 20 (02), N01. https://doi.org/10.22323/2.20020801. 